\title{
Article
}

\section{Resolving Site-Specific Energy Levels of Small-Molecule Donor-Acceptor Heterostructures Close to Metal Contacts}

\author{
Amani Benhnia ${ }^{1} \oplus$, Shinta Watanabe ${ }^{2}\left(\mathbb{D}\right.$, Rouzhaji Tuerhong ${ }^{1}$, Masato Nakaya ${ }^{2}$, Jun Onoe ${ }^{2}{ }^{\oplus}$ and \\ Jean-Pierre Bucher $1, *$ (D) \\ 1 Institutde Physiqueet Chimiedes Matériaux de Strasbourg (IPCMS), Université de Strasbourg, CNRS, \\ IPCMS UMR 7504, F-67034 Strasbourg, France; amani.benhnia@ipcms.unistra.fr (A.B.); \\ ruzaji@gmail.com (R.T.) \\ 2 Department of Energy Science and Engineering, Nagoya University, Furo-cho, Chikusa-ku, \\ Nagoya 464-8603, Japan; s-watanabe@energy.nagoya-u.ac.jp (S.W.); m-nakaya@energy.nagoya-u.ac.jp (M.N.); \\ j-onoe@energy.nagoya-u.ac.jp (J.O.) \\ * Correspondence: jean-pierre.bucher@ipcms.unistra.fr
}

check for updates

Citation: Benhnia, A.; Watanabe, S.; Tuerhong, R.; Nakaya, M.; Onoe, J.; Bucher, J.-P. Resolving Site-Specific Energy Levels of Small-Molecule Donor-Acceptor Heterostructures Close to Metal Contacts. Nanomaterials 2021, 11, 1618. https: / / doi.org/10.3390/ nano11061618

Academic Editor: Sergio Brutti

Received: 25 May 2021

Accepted: 17 June 2021

Published: 20 June 2021

Publisher's Note: MDPI stays neutral with regard to jurisdictional claims in published maps and institutional affiliations.

Copyright: (C) 2021 by the authors. Licensee MDPI, Basel, Switzerland. This article is an open access article distributed under the terms and conditions of the Creative Commons Attribution (CC BY) license (https:// creativecommons.org/licenses/by/ $4.0 /)$.

\begin{abstract}
The active material of optoelectronic devices must accommodate for contacts which serve to collect or inject the charge carriers. It is the purpose of this work to find out to which extent properties of organic optoelectronic layers change close to metal contacts compared to known properties of bulk materials. Bottom-up fabrication capabilities of model interfaces under ultrahigh vacuum and singleatom low temperature (LT)-STM spectroscopy with density functional theory (DFT) calculations are used to detect the spatial modifications of electronic states such as frontier-orbitals at interfaces. The system under consideration is made of a silver substrate covered with a blend of $\mathrm{C}_{60}$ and $\mathrm{ZnPc}$ molecules of a few monolayers. When $\mathrm{C}_{60}$ and $\mathrm{ZnPc}$ are separately adsorbed on $\mathrm{Ag}(111)$, they show distinct spectroscopic features in STM. However, when $\mathrm{C}_{60}$ is added to the $\mathrm{ZnPc}$ monolayer, it shows scanning tunneling spectra similar to $\mathrm{ZnPc}$, revealing a strong interaction of $\mathrm{C}_{60}$ with the $\mathrm{ZnPc}$ induced by the substrate. DFT calculations on a model complex confirm the strong hybridization of $\mathrm{C}_{60}$ with $\mathrm{ZnPc}$ layer upon adsorption on $\mathrm{Ag}(111)$, thus highlighting the role of boundary layers where the donor-acceptor character is strongly perturbed. The calculation also reveals a significant charge transfer from the Ag to the complex that is likely responsible for a downward shift of the molecular LUMO in agreement with the experiment.
\end{abstract}

Keywords: metal-organic interfaces; donor-acceptor molecular blends; scanning tunneling spectroscopy; self-assembly

\section{Introduction}

Organic optoelectronics, in the form of organic photovoltaics (OPVs) and organic light-emitting (OLEDs) devices, has undergone a rapid development in recent years which is largely attributable to unique advantages such as lightweight, mechanical flexibility, large area, transparency, and low fabrication cost [1-3]. Much research effort has been directed at improving the performance of devices. To date, the power conversion efficiency of OPV devices has passed the 15\% mark [4], whereas novel materials and device structures has allowed the external quantum efficiencies of OLEDs to exceed 30\% [5].

The active layer of bulk-heterojunctions typically consists of electron-donor and electron-acceptor molecules, sandwiched between two charge selective ohmic contacts. It has been shown that the nature of ohmic transitions at contacts of organic solar cells has a significant impact on their performance [6], and a better definition of energy level alignment of molecule-molecule and molecule-contact interfaces are key elements for the improvement of performance [7]. Thus, new interlayer materials have been introduced for work function control and to favor selectivity and chemical compatibility [8-10]. In 
particular, the molecule-metal interface is involved when ultrathin silver as well as silverdoped Al layers and grids of silver or gold are used as semi-transparent electrodes in OPV in combination (or not) with metal-oxides [11-15]. The fact that, various light-trapping strategies in OPV consist in incorporating large area nanostructures such as Ag layers and nanostructures [16] brings even more relevance to this question.

Here, this issue is addressed in the framework of molecular blends of donor-acceptor molecules that are particularly relevant for applications. In this context, the measurement of electronic properties remains challenging because of the difficulty of interpretation of bulk measurements for small length-scales. To evaluate the incidence of metal contacts on ultrathin layers of molecules, an approach with atomic-scale control is necessary. Scanning probes have proven to be particularly powerful in monitoring and characterizing the growth of molecular structures on surfaces. Considering that in situ UHV conditions are necessary for controlled self-assembly of molecules, this task is ideally addressed by resorting to STM spectroscopy, provided that relatively small donor and acceptor molecules are considered.

In this study, emphasis is therefore put on metallophthalocyanines (MPc) in combination with $\mathrm{C}_{60}$ molecules. Whereas such systems have been analyzed quite in detail by means of various ensemble averaging techniques [10,11,17-19], the study of blends of molecules, by STM is rather scarce and has been mainly addressed from the growth point of view [20-22]. Here, we perform an in-depth spectroscopic study by high-resolution LT-STM of a $\mathrm{ZnPc} / \mathrm{C}_{60}$ heterostructure in contact with a silver substrate. In addition, we aim at addressing the control of the molecular environment [23-25] and the charge transfer [26] which are important aspects of the preparation of optoelectronic devices.

\section{Methods and Experimental Results}

\subsection{Experimental Methods}

Experiments were performed in a UHV system with a base pressure $p<10^{-10}$ mbar, equipped with a low temperature scanning tunneling microscope (Modified Createc LTSTM). The Ag(111) single crystal was cleaned by repeated cycles of $\mathrm{Ne}^{+}$ion bombardment followed by thermal annealing at $500{ }^{\circ} \mathrm{C}$. The $\mathrm{ZnPc}$ and $\mathrm{C}_{60}$ molecules were evaporated from two $\mathrm{Al}_{2} \mathrm{O}_{3}$ crucible heated by means of a tantalum filament. Before the deposition, the $\mathrm{ZnPc}$ powder from Sigma-Aldrich (purity $>98 \%$ ) is degassed for several hours in UHV. The ZnPc molecules are then deposited at a rate of $0.2 \mathrm{~mL} / \mathrm{min}$ from the crucible held at a temperature of $180^{\circ} \mathrm{C}$ on the silver substrate kept at room temperature. The $\mathrm{C}_{60}$ powder from Sigma-Aldrich (98\% purity) has been sublimed at a crucible temperature of $240{ }^{\circ} \mathrm{C}$. The sample is then transferred into the STM chamber. All STM/STS measurements have been performed at $\mathrm{T}=77 \mathrm{~K}$. Tungsten tips are flash annealed in UHV and conditioned by indentation into an Au substrate. STM images were acquired in a constant current mode, the bias voltage is applied to the sample with respect to the tip kept at a virtual ground. The $\mathrm{dI} / \mathrm{dV}(\mathrm{V})$ signal was measured by a lock-in technique, superposing a rms modulation of $3.5 \mathrm{mV}$ at a frequency of $600 \mathrm{~Hz}$ to the sample bias. Wide range $\mathrm{dI} / \mathrm{dV}$ spectra are measured at a sample bias between $-2.0 \mathrm{~V}$ and $2.0 \mathrm{~V}$.

\subsection{Experimental Results}

The Ag (111) substrate is cleaned by repeated sputtering and annealing cycles. The molecular deposition is performed in an ultrahigh vacuum (UHV) chamber from two alumina crucibles, the first contains the $\mathrm{ZnPc}$ whereas the second one contains the $\mathrm{C}_{60}$, evaporation temperatures are $\mathrm{T}=180^{\circ} \mathrm{C}$ and $\mathrm{T}=240^{\circ} \mathrm{C}$ respectively. Both molecules are deposited onto the Ag substrate held at room temperatures. After deposition, the sample is transferred into the STM chamber held at a base pressure of $p=1 \times 10^{-11} \mathrm{mbar}$ where the STM experiments are performed at $\mathrm{T}=77 \mathrm{~K}$.

As an example, Figure $1 \mathrm{a}$ shows an STM image of a $\mathrm{C}_{60}$ island grown on a monolayer of $\mathrm{ZnPc}$ where both networks are well resolved. The relationship between the two structures is highlighted in the schematic view of Figure 1b. We anticipate that a two-monolayer-thick 
blend of donor and acceptor molecules in contact with a metal surface is sufficient to define the molecule-metal interface of a heterostructure. An incomplete $\mathrm{C}_{60}$ layer then has the advantage of presenting a different coordination of $\mathrm{C}_{60}$ molecules on top of the $\mathrm{ZnPc}$ layer, useful in the course of this study. Prior to growing the $\mathrm{C}_{60} / \mathrm{ZnPc}$ heterostructure on $\mathrm{Ag}(111)$, the growth mode of each molecular specie was investigated individually, see Figure S1. We found that the ZnPc forms a first uniform layer of flat laying molecules with a nearly square lattice, whereas the $C_{60}$ exhibits a compact layer-by-layer growth on $\operatorname{Ag}(111)$.
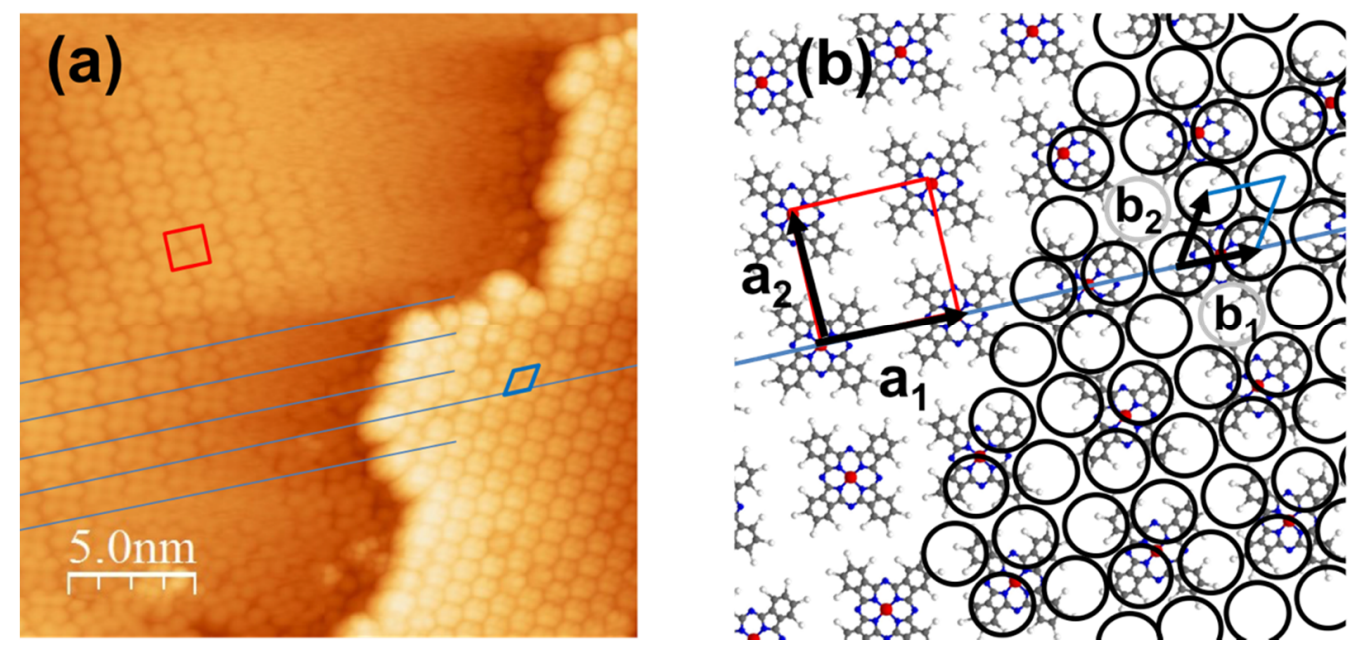

Figure 1. (a) STM topography of a $\mathrm{C}_{60}$ island grown on a $\mathrm{ZnPc}$ layer on $\mathrm{Ag}(111)$, simultaneously showing the molecular resolution of both lattices, see the red square and the blue diamond; the blue lines indicate rows of $\mathrm{ZnPc}$ molecules $(0.6 \mathrm{nA},-0.4 \mathrm{~V}$ and $\mathrm{T}=77 \mathrm{~K})$. (b) Magnified schematic view corresponding to the STM topography, where the $\mathrm{C}_{60}$ lattice (circles) is superposed on the $\mathrm{ZnPc}$ lattice. As indicated $\mathbf{a}_{\mathbf{1}}$ and $\mathbf{b}_{\mathbf{1}}$ are colinear.

Combined photoemission and inverse photoemission works already found a dramatic effect of the metal contact on the HOMO-LUMO gap of $\mathrm{C}_{60}$ that drops from $3.3 \mathrm{eV}$ for thick films to $2.3 \mathrm{eV}$ for a $\mathrm{C}_{60}$ monolayer on $\operatorname{Ag}(111)[27,28]$. At the same time, the information about $\mathrm{ZnPc}$ on substrates is scarce and no work has been done so far on silver. Here we find that two separate samples, one with a $C_{60}$ monolayer on $\operatorname{Ag}(111)$ and another one with a ZnPc monolayer on Ag(111) show very distinct STS spectra (Figure 2b,c) leading to different $\mathrm{HOMO}$ levels and HOMO-LUMO gaps. In particular, the $\mathrm{C}_{60} / \mathrm{Ag}(111)$ spectrum of Figure $2 b$ looks very much like the ones obtained in early studies [29-32] with same LUMO, LUMO+1 and HOMO. It is also noteworthy that spectra taken above $\mathrm{C}_{60}$ with different topographic contrasts (topmost hexagonal face or edge in Figure 2b) are identical. Surprisingly, when a $\mathrm{C}_{60}$ monolayer is deposited on top of a $\mathrm{ZnPc}$ layer, it is found that most resonances in the STS appear at same energies as for the $\mathrm{ZnPc}$ layer alone. This anomalous energy level alignment will be discussed in detail in the following.

As a matter of fact, the two peaks of $\mathrm{C}_{60} / \mathrm{ZnPc} / \mathrm{Ag}(111)$ at $-1.7 \mathrm{eV}$ and $+1.08 \mathrm{eV}$ and the shoulder at $0.45 \mathrm{eV}$ (Figure 1a) seem to come from the underlying $\mathrm{ZnPc}$ as can be observed from the $\mathrm{ZnPc} / \mathrm{Ag}(111)$ spectrum of Figure 2c. Additionally, two small satellites of the main peak at $1.08 \mathrm{eV}$ in Figure 1a seem to come from two remarkable features of $\mathrm{C}_{60} / \mathrm{Ag}(111)$ at +0.46 and $+1.6 \mathrm{eV}$ (compare Figure $\left.2 \mathrm{a}, \mathrm{b}\right)$. The small peak at $-0.31 \mathrm{eV}$ on $\mathrm{C}_{60} / \mathrm{ZnPc} / \mathrm{Ag}(111)$ (Figure 1a) which is absent on $\mathrm{C}_{60} / \mathrm{Ag}(111)$ (Figure 2b) also stems from the $\mathrm{ZnPc} / \mathrm{Ag}(111)$ (Figure 2c). The feature at $-0.31 \mathrm{eV}$ is not specific to $\mathrm{ZnPc} / \mathrm{Ag}(111)$ and has been observed for $\mathrm{MnPc} / \mathrm{Ag}(111)$ as well [33], showing strong evidence that this peak is substrate related. See also the case of FePc/ $\mathrm{Ag}(111)$ [34].

The energy levels gathered from the observation are summarized in Table 1 . The alignment for HOMO, LUMO, LUMO+1, and LUMO+2 suggests a strong hybridization of the $\mathrm{ZnPc}$ and $\mathrm{C}_{60}$ layers induced by the metal substrate. In addition, for all cases, a HOMO- 
LUMO gap comprised between 2.0 and $2.3 \mathrm{eV}$ is found, not considering the small feature at $-0.3 \mathrm{eV}$. For comparison, the corresponding molecular orbital energies for thick-layer, bulk heterostructures are shown as well [17]. It is found that the frontier orbitals of the adsorbed $\mathrm{ZnPc}$ are downward shifted by about $0.35 \mathrm{eV}$ compared to the bulk heterostructure whereas the LUMO-level of the adsorbed $\mathrm{C}_{60}$ appears relatively unperturbed at $+0.46 \mathrm{eV}$. The downward shifting of frontier orbitals compared to experimental bulk values is expected and is clearly an effect of the adsorption on the metal surface. See also the calculation in the next section. Regarding the $\mathrm{C}_{60} / \mathrm{ZnPc}$ blend on $\mathrm{Ag}(111)$, a weak shoulder at $+0.4 \mathrm{eV}$ and an intense peak at $+1.1 \mathrm{eV}$ are observed above the $\mathrm{C}_{60}$. The LUMO level can tentatively be assimilated to the intense peak at $+1.1 \mathrm{eV}$, corresponding to the $\mathrm{LUMO}+1$ of $\mathrm{ZnPc}$ on $\mathrm{Ag}$ (111). These results reveal an inversion of the usual donor-acceptor picture of $\mathrm{ZnPc}$ and $\mathrm{C}_{60}$ close to the contact.

(a)

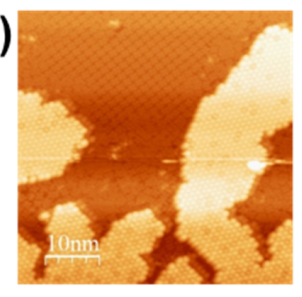

(b)

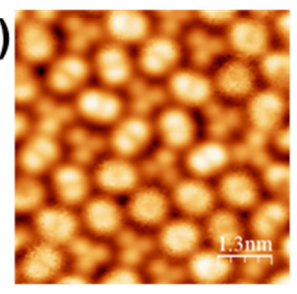

(c)

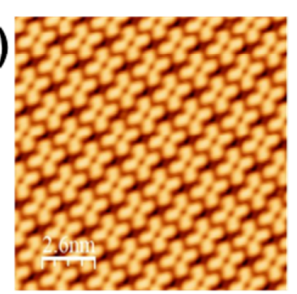

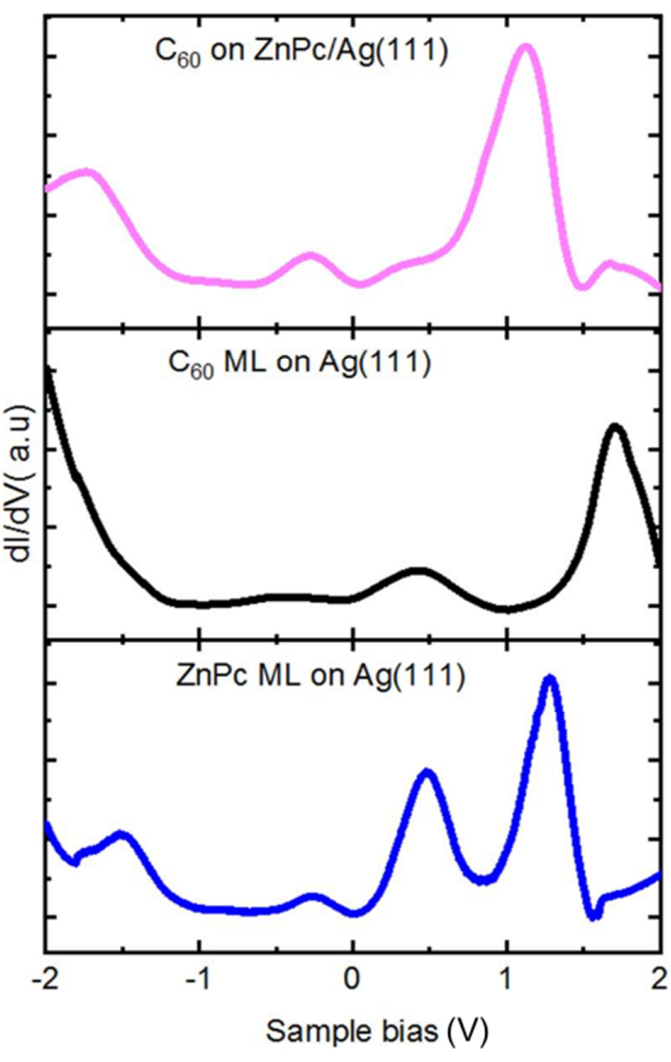

Figure 2. STM topography and differential conductance spectra for (a) $C_{60}$ molecule islands grown on $\mathrm{ZnPc} / \mathrm{Ag}(111)$. For comparison: (b) $\mathrm{C}_{60}$ molecules on $\mathrm{Ag}(111)$; the topograph shows contrasts of either the topmost hexagon ring or the $6: 6$ bond separating two adjacent hexagon rings of the $C_{60}$ molecule. (c) Face-on $\mathrm{ZnPc}$ molecules on $\mathrm{Ag}(111)$. For the dI/dV spectroscopy, the feedback loop was opened at $0.7 \mathrm{nA}$ and $-0.3 \mathrm{~V}$.

Table 1. Experimental energy levels in $\mathrm{eV}$.

\begin{tabular}{|c|c|c|c|c|c|c|}
\hline & ZnPc/Ag(111) & $\mathrm{C}_{60} / \mathrm{Ag}(111)$ & $\mathrm{C}_{60} / \mathrm{ZnPc} / \mathrm{Ag}(111)$ & $\mathrm{ZnPc} *$ & $\mathrm{C}_{60} *$ & $7 \mathrm{C}_{60}+4 \mathrm{ZnPc} / \mathrm{Ag}(111) * *$ \\
\hline LUMO+2 & - & +1.6 & +1.6 & & & +2.35 \\
\hline LUMO+1 & +1.1 & - & +1.1 & & & +1.39 \\
\hline LUMO & +0.48 & +0.46 & +0.4 & +0.82 & +0.4 & +0.32 \\
\hline SS & -0.3 & - & -0.3 & & & \\
\hline HOMO & -1.6 & -1.9 & -1.7 & -1.16 & -1.9 & -1.26 \\
\hline
\end{tabular}

${ }^{*}$ values for bulk heterostructures from Park et al. [17]. ${ }^{* *}$ Calculation (this work), the listed values correspond to peak values of the DOS. 
It has been shown that small differences in the charge distribution at the bonding site of $\mathrm{C}_{60}$ can be responsible for as much as $0.6 \mathrm{eV}$ increase in the gap when going from a silver to a gold substrate [30], demonstrating a large impact of the substrate. Although some analytical treatments have been applied to understand the sensitivity to the $\mathrm{C}_{60}$ environment $[27,31]$ a better treatment of screening effects can only be addressed through a numerical approach. In order to improve our understanding of these effects, that are likely triggered by the on-surface adsorption of the molecular species, we made a detailed simulation of the adsorption of a $\mathrm{C}_{60} / \mathrm{ZnPc}$ complex on a silver substrate.

\section{Model Calculation and Discussion}

Due to the large number of atoms involved in the heterostructure, a model calculation on this system is very challenging. Therefore, to simulate the real system, we consider a $\mathrm{C}_{60}$ heptamer cluster lying on top of a $\mathrm{ZnPc}$ layer made of four $\mathrm{ZnPc}$ molecules. In the following, we call it the $7 \mathrm{C}_{60}+4 \mathrm{ZnPc}$ complex (see Figure 3). The complex is designed to reproduce locally the relationship between the two lattices in accordance with Figure 1, see also Figure S1 and the SM for details. For the purpose of comparison, we considered both, a calculation of a free complex in the gas phase prior to deposition, and a calculation of the same complex deposited on a $\mathrm{Ag}(111)$ slab. The computational method is described in Appendix A.

All the structures have been relaxed prior to the DFT calculation to get the equilibrium configuration; see the side view of Figure 3a. The DFT calculation has been performed in the static configuration of the $C_{60}$ molecules, where all the $C_{60}$ molecules have the same face-on orientation of the $\mathrm{C}_{60}$ hexagon on the $\mathrm{ZnPc}$ layer. This assumption seems to be valid, at least judging from the experiment on the bulk material whose rotational motions are frozen below $90 \mathrm{~K}$ [35]. Since our experiments have been done at $77 \mathrm{~K}$, we believe it is legitimate to assume a static configuration in your calculations. The calculation for the 6:6 bond orientation of adjacent six-membered rings of $\mathrm{C}_{60}$ and $\mathrm{ZnPc}$ were also tested, however, the energy of this system was slightly higher.

Because we explore the most stable configuration of molecules in our model, we did not restrict the symmetry in our calculation. Considering the orientation of $\mathrm{C}_{60}$ molecules and the interaction between $\mathrm{ZnPc}$ and $\mathrm{C}_{60}$, a structure with high symmetry is not always the most stable. As a result, we do not expect the same local density of states (LDOS) between apparently symmetric configurations of $\mathrm{C}_{60}$ molecules on $\mathrm{ZnPc}$ as one would expect by considering the geometry prior to the optimization process.

Let us first discuss the LDOS of Figure $3 b$ for the gas phase situation. The calculation shows distinct spectra on $\mathrm{C}_{60}$ and $\mathrm{ZnPc}$ (lower panel of Figure $3 \mathrm{~b}$ ) revealing only a weak hybridization between $\mathrm{C}_{60}$ and $\mathrm{ZnPc}$, except perhaps for the states above $3 \mathrm{eV}$. The HOMOLUMO gap of about $1.8 \mathrm{eV}$ that can be drawn from the LDOS is only weakly underestimated compared to the experimental value of $2 \mathrm{eV}$. Remarkably, the LDOS on the different $\mathrm{C}_{60}$ of the heptamer show differences. This may be due to different positions of the $\mathrm{C}_{60}$ above the $\mathrm{ZnPc}$, thus experiencing different interactions with the underlying $\mathrm{ZnPc}$ (see the charge density distribution). Another reason may be that each $\mathrm{ZnPc}$ molecule in the $4 \mathrm{ZnPc}+7$ $\mathrm{C}_{60}$ complex is distorted to a different degree. The splitting of individual resonances has been observed in a previous calculation performed on $\mathrm{C}_{60}$ only [36].

It is instructive to compare this situation to the experimentally more relevant one of the complex adsorbed on Ag(111) substrate shown in Figure 3c. The LDOS now reveals a strong hybridization of $\mathrm{C}_{60}$ and $\mathrm{ZnPc}$ states, which is apparent in Figure $3 \mathrm{c}$ whereas the HOMO-LUMO gap of about $1.8 \mathrm{eV}$ is unchanged and compares well with experimental results. In addition, a significant broadening of relevant HOMO and LUMO peaks is observed upon adsorption of the complex on the $\mathrm{Ag}(111)$ surface (compare Figure 3b,c). The strong interaction is also reflected in the deformation of the $\mathrm{ZnPc}$ molecules at the interface with the $\mathrm{C}_{60}$ molecules (Figure 3a). The important charge transfer from the silver substrate to the complex (see the analysis below) leads to a significant downwards shift of 
the Fermi level which is not in the middle of the HOMO-LUMO gap anymore but lies just below the LUMO (Figure 3c), meaning that the simulated system is a n-type semiconductor.

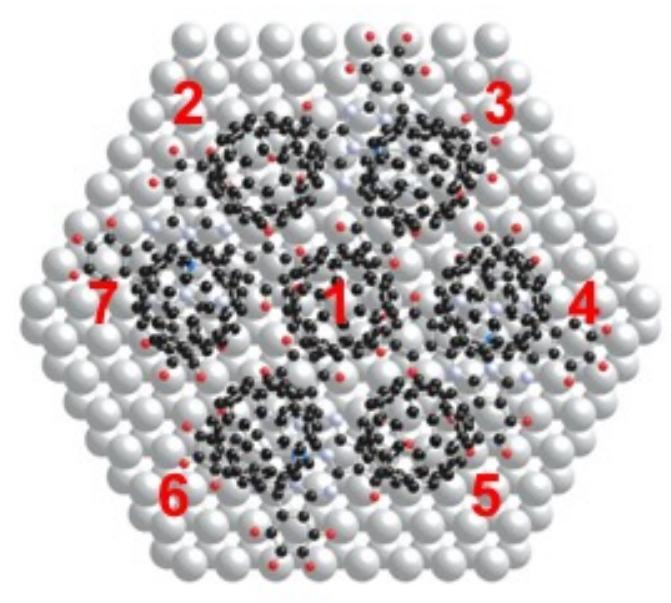

(a)
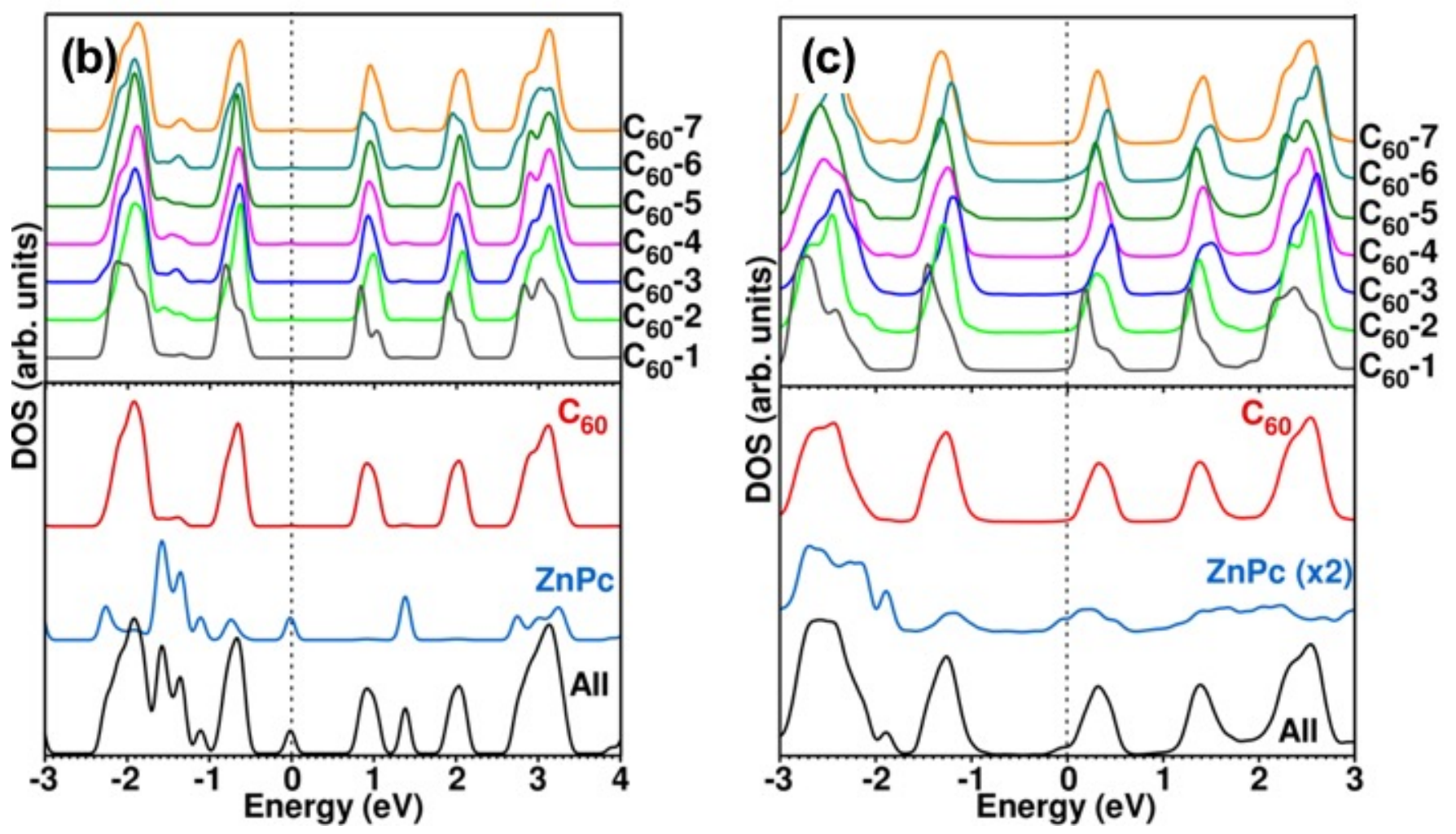

Figure 3. (a) $7 \mathrm{C}_{60}+4 \mathrm{ZnPc}$ model complex adsorbed on $\mathrm{Ag}(111)$ slab used for the DFT calculation. The side view shows the structure of the complex after relaxation. LDOS on the a $7 \mathrm{C}_{60}+4 \mathrm{ZnPc}$ model complex (b) in the gas phase (c) adsorbed on a $\mathrm{Ag}(111)$ slab. The LDOS spectra are numbered according to the position of in the complex, $\mathrm{C}_{60}-1$ being in the center whereas $\mathrm{C}_{60}-2$ to $\mathrm{C}_{60}-7$ are on the perimeter. The lower panels show total DOS on $\mathrm{C}_{60}, \mathrm{ZnPc}$ and all together. The energy axis represents $\left(\mathrm{E}-\mathrm{E}_{\mathrm{F}}\right)$.

Additionally, for both cases, free and adsorbed, we notice a difference in the LDOS of 6-fold coordinated $\mathrm{C}_{60}$ and the 3 -fold coordinated $\mathrm{C}_{60}$ in the $4 \mathrm{ZnPc}+7 \mathrm{C}_{60}$ complex model. To investigate this aspect further, we show in Figure 4 conductance spectra taken at various sites above a $\mathrm{C}_{60}$ island on $\mathrm{ZnPc} / \mathrm{Ag}(111)$, corresponding to nearest neighbor (NN) $\mathrm{C}_{60}$ from $2 \mathrm{NN}$ to $6 \mathrm{NN}$. The calculation correctly reproduces that the $\mathrm{C}_{60}$ with 6 neighbors (the central molecule of the heptamer cluster, Figure 3a) experiences a downward shift of both the HOMO and the LUMO compared to the $\mathrm{C}_{60}$ with 3 neighbors (outer molecules 
of the cluster, from $\mathrm{C}_{60}-2$ to $\mathrm{C}_{60}-7$ in Figure 3). As can be seen by comparing with the experimental conductance spectra of Figure 4, the trend is the same although the difference as a function of the $\mathrm{C}_{60}$ environment is not as large as observe in the experiments. In particular, we observe that the spectra for 3, 4, and $5 \mathrm{NN}$ of $\mathrm{C}_{60}$ on $\mathrm{ZnPc}$ look very much like the $\mathrm{C}_{60}$ in direct contact with the $\mathrm{Ag}(111)$ substrate (see Figure $2 \mathrm{~b}$ ). This is clear from the HOMO-LUMO gap which is significantly larger than the LUMO-LUMO+1 gap in good agreement with the calculation of Figure 3c. It is not clear yet why the lower coordination in Figure 4 shows a dominant $\mathrm{C}_{60}$ feature, with a noticeable exception of the $2 \mathrm{NN}$ case which looks more like the full coordination $(6 \mathrm{NN})$. It must be emphasized that all spectra in Figure $4 \mathrm{~b}$ have been tested for reproducibility on different parts of the $\mathrm{C}_{60}$ molecular islands. Unfortunately, it was not possible to fully probe these results by means of the calculation, due to the poor stability of clusters with small and intermediate NN numbers in the simulation. For example, the calculation with one $\mathrm{C}_{60}$ missing did not converge, i.e., the force acting on the $\mathrm{C}$ atoms of $\mathrm{C}_{60}$ did not fall below the convergence criteria $(0.01 \mathrm{eV} / \AA)$ and the $\mathrm{C}_{60}$ kept on moving. This reflects the facts that voids are extremely difficult to simulate in finite systems (finite number of $\mathrm{Ag}$ atoms and $\mathrm{ZnPc}$ ).

(a)

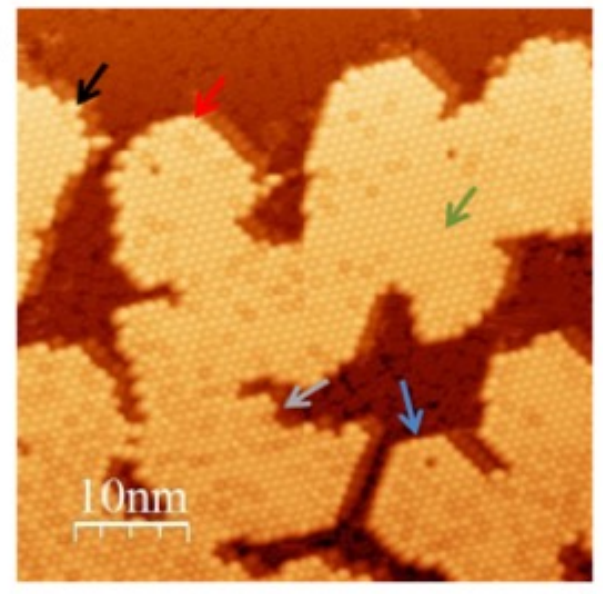

(b)

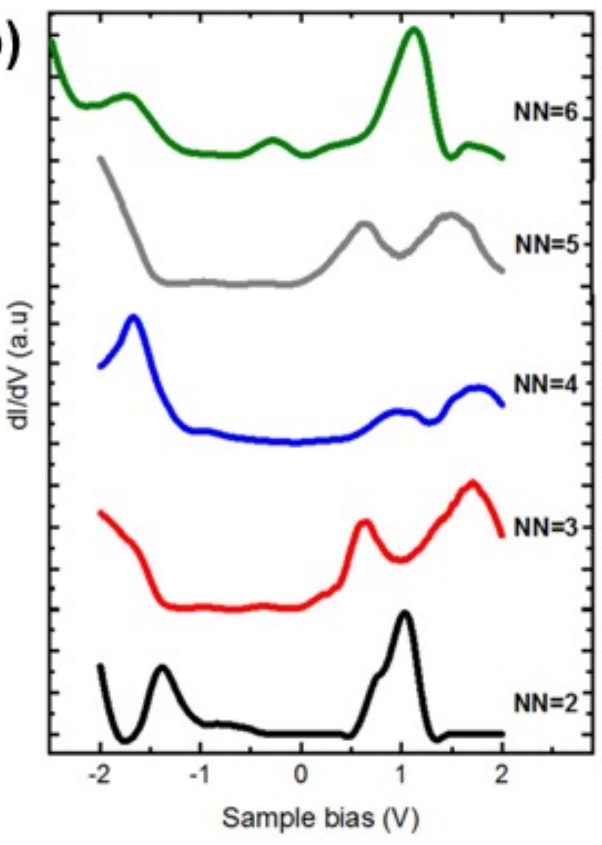

Figure 4. (a) STM topography of $\mathrm{C}_{60}$ islands grown on $\mathrm{ZnPc} / \mathrm{Ag}(111)$. The arrows are highlighting the different coordination of $\mathrm{C}_{60}$ on top of the ZnPc layer. (b) Differential conductance spectra (dI/dV) of $\mathrm{C}_{60}$ molecule absorbed on a monolayer $\mathrm{ZnPc}$ on $\mathrm{Ag}$ (111) corresponding to different numbers of nearest neighbors in (a). STS were recorded for $\mathrm{C}_{60}$ molecules surrounded by 2 (black curve), 3 (red curve), 4 (blue curve), 5 (grey curve), and 6 (green curve) $\mathrm{C}_{60}$ molecule. Feedback loop was opened at $0.7 \mathrm{nA}$ and $-0.3 \mathrm{~V}$.

The Mulliken population analysis (Figure S2) provides additional information on the effect of the substrate. In the absence of the silver substrate the four $\mathrm{ZnPc}$ donate 1.0 e to the seven $\mathrm{C}_{60}$ molecules which is about 0.14 e per $\mathrm{C}_{60}$. In the presence of the silver substrate, however, the calculation shows that the silver donates to both, the $\mathrm{ZnPc}$ and the $\mathrm{C}_{60}$. We notice a large charge transfer from the silver (as much as $12 \mathrm{e}$ ) to the complex. This leads ultimately to about 0.5 e on each $\mathrm{C}_{60}$ molecule and 2 e on each of the ZnPc. These results confirm that the donor and acceptor character of $\mathrm{ZnPc}$ and $\mathrm{C}_{60}$ respectively is strongly perturbed in the vicinity of a silver electrode, since both types of molecules are now bearing a negative charge. Although the simulation gives the correct trend, the charge transfer is probably overestimated due to the finite size of the silver substrate in the simulation which underestimates the delocalization of free electrons in silver. 
A strong reduction of the distance between the $\mathrm{C}_{60}$ and the $\mathrm{ZnPc}$ layer is observed upon adsorption, leading to a bending of the $\mathrm{ZnPc}$. The average distance from the $\mathrm{C}_{60}$ to the ZnPc plane is reduced from 2.35 to $1.83 \AA$ as shown in Figure 3. As a result, the adsorption of the complex on the $\mathrm{Ag}(111)$ substrate, produces a stronger interaction between $\mathrm{ZnPc}$ and $\mathrm{C}_{60}$ molecular layers that is also reflected in the significant broadening of the DOS peaks (Figure 3). In summary, both, the calculation and the experiment show a similar intriguing energy-level alignment for a $\mathrm{C}_{60}$ molecule on top of $\mathrm{ZnPc} / \mathrm{Ag}(111)$. Our study furthermore highlights the presence of a Fermi-level that is located far from the mid-gap position, which is rather uncommon for an undoped organic semiconductor complex.

\section{Conclusions}

Our findings show that the proximity of contacts significantly alters the donor-acceptor picture originated from conventional organic electronics. When $\mathrm{C}_{60}$ is deposited on a $\mathrm{ZnPc}$ monolayer on a metal substrate, it shows similar STS (alignment of peaks) than ZnPc revealing a strong hybridization of the $\mathrm{C}_{60}$ with the $\mathrm{ZnPc}$ in the presence of the substrate. The calculation, including the silver substrate, clearly shows that the charge transfer from the silver contact cannot be neglected, leading to a downward shift of the molecular LUMO in good agreement with the experiment. The simulation confirms the strong hybridization of $\mathrm{C}_{60}$ layer with $\mathrm{ZnPc}$ layer upon adsorption on $\mathrm{Ag}(111)$. It is also found that the $\mathrm{dI} / \mathrm{dV}$ spectra are very sensitive to the $\mathrm{C}_{60}$ nearest neighbor environment, thus underlining the importance of the boundary layers. Finally, one can anticipate that a significant charge transfer to the molecules is only expected for the first molecular layers of $\mathrm{ZnPc}_{\mathrm{n}}$ an $\mathrm{C}_{60}$, those in the vicinity of the substrate. In actual optoelectronic devices, layers are several $10 \mathrm{~nm}$ thick, and the perturbation relaxes to a negligible value inside the layer. The findings are relevant for any optoelectronic system utilizing charge carrier injection or collection at contacts and interfaces and for photovoltaic devices in particular.

Supplementary Materials: The following are available online at https:/ / www.mdpi.com/article/10 $.3390 /$ nano11061618/s1. Figure S1. Unit cell vectors corresponding to the ZnPc molecules. Inset: atomic resolution of the $\mathrm{Ag}(111)$; Figure S2. Mulliken charge distribution on the $4 \mathrm{ZnPc}+7 \mathrm{C}_{60}$ complex in the gas phase (left) and adsorbed on the $\mathrm{Ag}(111)$ substrate (right).

Author Contributions: A.B. performed the experiments, analyzed the data, and contributed to the writing of the manuscript. J.-P.B. conceived the experiments, analyzed the data, and wrote the article. S.W. performed the calculation. R.T. contributed to the experiments and data analysis. M.N. and J.O. provided valuable suggestions. J.-P.B. and J.O. acquired the funding. All authors have read and agreed to the published version of the manuscript.

Funding: Support from the Agence Nationale de la Recherche in France via the project LabEx NIE: ANR-11- LABX-0058_NIE is acknowledged. The present work was partially supported by the JapanFrance Research Cooperative Program between the JSPS (Japan Society for the Promotion of Science) and CNRS (Center National de la Recherche Scientifique).

Data Availability Statement: The data presented in this study are available on request from the corresponding author.

Conflicts of Interest: The authors declare no conflict of interest.

\section{Appendix A}

The model for the calculation is composed of four $\mathrm{ZnPc}$ and seven $\mathrm{C}_{60}$ molecules adsorbed on a two layer $\mathrm{Ag}(111)$ substrate, leading to a total of 968 atoms. A slab model with a $2.5 \mathrm{~nm}$ vacuum layer along the c-axis was adopted. The gas phase calculation was performed using the $4 \mathrm{ZnPc}+7 \mathrm{C}_{60}$ model complex in a $3.608 \times 3.608 \times 2.5 \mathrm{~nm}^{3}$ vacuum box. The distance between the $4 \mathrm{ZnPc}+7 \mathrm{C}_{60}$ complexes in neighboring cells is sufficient to prevent any artificial interaction between them. The geometry optimization and LDOS calculations were performed by DFT-D3 [37] method using the CASTEP [38], which is based on the ultrasoft pseudopotential plane-wave method [39]. Considering the calculation cost, 
the geometry optimization of the $\mathrm{Ag}(111)$ surface was performed first, and then used for the calculation of $4 \mathrm{ZnPc}+7 \mathrm{C}_{60}$ complex on $\mathrm{Ag}(111)$. The exchange-correlation potential was considered within the generalized gradient approximation (GGA) proposed by Perdew, Burke, and Ernzerhof (PBE) [40]. The cutoff energy of the plane wave was $400 \mathrm{eV}$, and the reciprocal space integration was done using single gamma Monkhorst-Pack grids [41]. The geometry optimization was performed until the residual forces and stresses dropped below $0.01 \mathrm{eV} / \AA$ and $0.02 \mathrm{GPa}$, respectively.

\section{References}

1. Kippelen, B.; Bredas, J.L. Organic photovoltaics. Energy Environ. Sci. 2009, 2, 251-261. [CrossRef]

2. Ostroverkhova, O. (Ed.) Handbook of Organic Materials for Optical and (Opto)Electronic Devices; Woodhead Publishing: Cambridge, UK, 2013.

3. Qiao, Q. (Ed.) Organic Solar Cells: Materials, Devices, Interfaces, and Modeling; CRC Press: New York, NY, USA, 2015.

4. Wang, R.; Yuan, J.; Wang, R.; Han, G.; Huang, T.; Huang, W.; Xue, J.; Wang, H.; Zhang, C.; Zhu, C.; et al. Rational Tuning of Molecular Interaction and Energy Level Alignment Enables High-Performance Organic Photovoltaics. Adv. Mater. 2019, 31, 1904215. [CrossRef]

5. Sun, J.W.; Lee, J.-H.; Moon, C.-K.; Kim, K.-H.; Shin, H.; Kim, J.J. A Fluorescent Organic Light-Emitting Diode with $30 \%$ External Quantum Efficiency. Adv. Mater. 2014, 26, 5684-5688. [CrossRef]

6. Tan, J.K.; Png, R.Q.; Zhao, C.; Ho, P.K.H. Ohmic transition at contacts key to maximizing fill factor and performance of organic solar cells. Nat. Comm. 2018, 9, 3269. [CrossRef]

7. D'Avino, G.; Muccioli, L.; Castet, F.; Poelking, C.; Andrienko, D.; Soos, Z.G.; Cornil, J.; Beljonne, D. Electrostatic phenomena in organic semiconductors: Fundamentals and implications for photovoltaics. J. Phys. Condens. Matter 2016, 28, 433002. [CrossRef]

8. Ratcliff, E.L.; Zacher, B.; Armstrong, N.R. Selective Interlayers and Contacts in Organic Photovoltaic Cells. J. Phys. Chem. Lett. 2011, 2, 1337-1350. [CrossRef] [PubMed]

9. Lai, T.-H.; Tsang, S.W.; Manders, J.R.; Chen, S.; So, F. Properties of interlayer for organic photovoltaics. Mater. Today 2013, 16, 424-432. [CrossRef]

10. Fleetham, T.B.; Mudrick, J.; Cao, W.; Klimes, K.; Xue, J.; Li, J. Efficient Zinc Phthalocyanine/C 60 Heterojunction Photovoltaic Devices Employing Tetracene Anode Interfacial Layers. ACS Appl. Mater. Interfaces 2014, 6, 7254-7259. [CrossRef] [PubMed]

11. Schubert, S.; Hermenau, M.; Meiss, J.; Müller-Meskamp, L.; Leo, K. Oxide Sandwiched Metal Thin-Film Electrodes for Long-Term Stable Organic Solar Cells. Adv. Funct. Mater. 2012, 22, 4993-4999. [CrossRef]

12. Lee, J.-Y.; Connor, S.T.; Cui, Y.; Peumans, P. Solution-Processed Metal Nanowire Mesh Transparent Electrodes. Nano Lett. 2008, 8 , 689-692. [CrossRef]

13. Chiba, T.; Kumagai, D.; Udagawa, K.; Watanabe, Y.; Kido, J. Dual mode OPV-OLED device with photovoltaic and light-emitting functionalities. Sci. Rep. 2018, 8, 11472. [CrossRef] [PubMed]

14. Zhang, S.Q.; Ye, L.; Hou, J. Breaking the 10\% Efficiency Barrier in Organic Photovoltaics: Morphology and Device Optimization of Well-Known PBDTTT Polymers. Adv. Energy Mater. 2016, 6, 1502529. [CrossRef]

15. Zhao, W.; Qian, D.; Zhang, S.; Li, S.; Inganäs, O.; Gao, F.; Hou, J. Fullerene-Free Polymer Solar Cells with over $11 \%$ Efficiency and Excellent Thermal Stability. Adv. Mater. 2016, 28, 4734-4739. [CrossRef] [PubMed]

16. Bi, Y.G.; Feng, J.; Ji, J.-H.; Yi, F.-S.; Li, Y.-F.; Liu, Y.-F.; Zhang, X.-L.; Sun, H.-B. Nanostructures induced light harvesting enhancement in organic photovoltaics. Nanophotonics 2018, 7,371-391. [CrossRef]

17. Park, S.H.; Jeong, J.G.; Kim, H.-J.; Park, S.-H.; Cho, M.-H.; Cho, S.W.; Yi, Y.; Heo, M.Y.; Sohn, H. The electronic structure of C60/ZnPc interface for organic photovoltaic device with blended layer architecture. Appl. Phys. Lett. 2010, 96, 013302. [CrossRef]

18. Zeng, W.; Yong, K.S.; Kam, Z.M.; Zhu, F.; Li, Y. Effect of blend layer morphology on performance of ZnPc:C60-based photovoltaic cells. Appl. Phys. Lett. 2010, 97, 133304. [CrossRef]

19. Tietze, M.L.; Tress, W.; Pfutzner, S.; Schunemann, C.; Burtone, L.; Riede, M.; Leo, K. Correlation of open-circuit voltage and energy levels in zinc-phthalocyanine: $\mathrm{C}_{60}$ bulk heterojunction solar cells with varied mixing ratio. Phys. Rev. B Condens. Matter Mater. Phys. 2013, 88, 085119. [CrossRef]

20. Stöhr, M.; Wagner, T.; Gabriel, M.; Weyers, B.; Möller, R. Binary Molecular Layers of $C_{60}$ and Copper Phthalocyanine on Au(111): Self-Organized Nanostructuring. Adv. Funct. Mater. 2001, 11, 175. [CrossRef]

21. Samuely, T.; Liu, S.-X.; Haas, M.; Decurtins, S.; Jung, T.A.; Stöhr, M. Self-Assembly of Individually Addressable Complexes of $\mathrm{C}_{60}$ and Phthalocyanines on a Metal Surface: Structural and Electronic Investigations. J. Phys. Chem. C 2009, 113, 19373-19375. [CrossRef]

22. Jin, W.; Liu, Q.; Dougherty, D.B.; Cullen, W.G.; Reutt-Robey, J.E.; Weeks, J.; Robey, S.W. C 60 chain phases on ZnPc/Ag(111) surfaces: Supramolecular organization driven by competing interactions. J. Chem. Phys. 2015, 142, 101910. [CrossRef]

23. Wang, L.; Guo, S.; Zhou, K.; Ma, W. Control of the molecular orientation in small molecule-based organic photovoltaics. Sustain. Energy Fuels 2020, 4, 4934-4955. [CrossRef]

24. Onoe, J.; Watanabe, S.; Kato, S.; Nakaya, M.; Bucher, J.P. Spectroscopic and theoretical studies on the structural, electronic, and optical properties of zinc octaethylporphyrin $/ \mathrm{C}_{60}$ co-deposited films. J. Chem. Phys. 2017, 147, 214701. [CrossRef] [PubMed] 
25. Wang, Z.; Miyadera, T.; Yamanari, T.; Yoshida, Y. Templating Effects in Molecular Growth of Blended Films for Efficient Small-Molecule Photovoltaics. ACS Appl. Mater. Interfaces 2014, 6, 6369-6377. [CrossRef] [PubMed]

26. Otero, R.; Vázquez de Parga, A.L.; Gallego, J.M. Electronic, structural and chemical effects of charge-transfer at organic/inorganic interfaces. Surf. Sci. Rep. 2017, 72, 105-145. [CrossRef]

27. Hesper, R.; Tjeng, L.H.; Sawatzky, G.A. Strongly reduced band gap in a correlated insulator in close proximity to a metal. Europhys. Lett. 1997, 40, 177. [CrossRef]

28. Schwedhelm, R.; Kipp, L.; Dallmeyer, A.; Skibowski, M. Experimental band gap and core-hole electron interaction in epitaxial $\mathrm{C}_{60}$ films. Phys. Rev. B Condens. Matter Mater. Phys. 1998, 58, 13176. [CrossRef]

29. Lu, X.; Grobis, M.; Khoo, K.H.; Louie, S.G.; Crommie, M.F. Spatially Mapping the Spectral Density of a Single $\mathrm{C}_{60}$ Molecule. Phys. Rev. Lett. 2003, 90, 096802. [CrossRef]

30. Lu, X.; Grobis, M.; Khoo, K.H.; Louie, S.G.; Crommie, M.F. Charge transfer and screening in individual $\mathrm{C}_{60}$ molecules on metal substrates: A scanning tunneling spectroscopy and theoretical study. Phys. Rev. B Condens. Matter Mater. Phys. 2004, $70,115418$. [CrossRef]

31. Fernández Torrente, I.; Franke, K.J.; Pascual, J.I. Spectroscopy of $\mathrm{C}_{60}$ single molecules: The role of screening on energy level alignment. J. Phys. Condens. Matter 2008, 20, 184001. [CrossRef]

32. Schulze, G.; Franke, K.J.; Pascual, J.I. Resonant heating and substrate-mediated cooling of a single $\mathrm{C}_{60}$ molecule in a tunnel junction. New J. Phys. 2008, 10, 065005. [CrossRef]

33. Tuerhong, R.; Ngassam, F.; Watanabe, S.; Onoe, J.; Alouani, M.; Bucher, J.P. Two-Dimensional Organometallic Kondo Lattice with Long-Range Antiferromagnetic Order. J. Phys. Chem. C 2018, 122, 20046-20054. [CrossRef]

34. Gopakumar, T.G.; Brumme, T.; Kröger, J.; Toher, C.; Cuniberti, G.; Berndt, R. Coverage-Driven Electronic Decoupling of Fe-Phthalocyanine from a Ag(111) Substrate. J. Phys. Chem. C 2011, 115, 12173-12179. [CrossRef]

35. Dolbin, A.V.; Esel'son, V.B.; Gavrilko, V.G.; Manzhelii, V.G.; Vinnikov, N.A.; Basnukaeva, R.M. The effect of glass transition in fullerite $\mathrm{C}_{60}$ on Ar impurity diffusion. Low Temp. Phys. 2013, 39, 370. [CrossRef]

36. De Menech, M.; Saalmann, U.; Garcia, M.E. Energy-resolved STM mapping of $\mathrm{C}_{60}$ on metal surfaces: A theoretical study. Phys. Rev. B 2006, 73, 155407. [CrossRef]

37. Grimme, S.; Antony, J.; Ehrlich, S.; Krieg, S. A consistent and accurate ab initio parametrization of density functional dispersion correction (DFT-D) for the 94 elements H-Pu. J. Chem. Phys. 2010, 132, 154104. [CrossRef] [PubMed]

38. Clark, S.J.; Segall, M.D.; Pickard, C.J.; Hasnip, P.J.; Probert, M.J.; Refson, K.; Payne, M.C. First principles methods using CASTEP. Z. Kristallogr. Cryst. Mater. 2005, 220, 567. [CrossRef]

39. Vanderbilt, D. Soft self-consistent pseudopotentials in a generalized eigenvalue formalism. Phys. Rev. B Condens. Matter Mater. Phys. 1990, 41, 7892-7895. [CrossRef]

40. Perdew, J.P.; Burke, K.; Ernzerhof, M. Generalized gradient approximation made simple. Phys. Rev. Lett. 1996, 77, $3865-3868$. [CrossRef]

41. Monkhorst, H.; Pack, J. Special points for Brillouin-zone integrations. Phys. Rev. B Condens. Matter Mater. Phys. 1976, 13, 5188-5192. [CrossRef] 